\title{
Xavier Orville, Ascesa e caduta di un dittatore antillano
}

\section{Ilaria Vitali}

\section{OpenEdition}

\section{Journals}

\section{Edizione digitale}

URL: http://journals.openedition.org/studifrancesi/28242

DOI: 10.4000/studifrancesi.28242

ISSN: 2421-5856

\section{Editore}

Rosenberg \& Sellier

\section{Edizione cartacea}

Data di pubblicazione: 31 décembre 2006

Paginazione: 651

ISSN: 0039-2944

\section{Notizia bibliografica digitale}

Ilaria Vitali, «Xavier Orville, Ascesa e caduta di un dittatore antillano », Studi Francesi [Online], 150 (L | III) | 2006, online dal 30 novembre 2015, consultato il 08 novembre 2020. URL : http://

journals.openedition.org/studifrancesi/28242 ; DOI : https://doi.org/10.4000/studifrancesi.28242

Questo documento è stato generato automaticamente il 8 novembre 2020 .

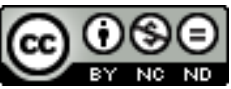

Studi Francesi è distribuita con Licenza Creative Commons Attribuzione - Non commerciale - Non opere derivate 4.0 Internazionale. 


\title{
Xavier Orville, Ascesa e caduta di un dittatore antillano
}

\author{
Ilaria Vitali
}

\section{NOTIZIA}

XAVIER ORVILLE, Ascesa e caduta di un dittatore antillano, traduzione di Vilma PORRO, Roma, Voland, 2006, pp. 121.

1 Il romanzo di Xavier Orville, Moi, Trésilien-Théodore Auguste, edito da Stock nel 1996, raggiunge finalmente il pubblico italiano, nella traduzione di Vilma Porro, edita da Voland. Come sottolinea il titolo nella versione italiana, l'opera narra l'ascesa e la caduta di un dittatore immaginario, Trésilien-Théodore Augustin, che si proclama Generale-Presidente a vita della Martinica, facendosi portavoce del «Grande Balzo in Avanti», che prevede, tra sopraffazioni, abusi e umiliazioni, persino la soppressione del sabato e delle ore superflue. Nonostante l'ironia e l'aperta finzionalità, il romanzo offre una spietata riflessione sul potere, in cui è facile intravedere riferimenti espliciti alla storia della Martinica. Scrive Orville: «Pour ma part, j'écris d'une terre violente, née du chaos, et que continuent à visiter régulièrement les cyclones, les tremblements de terre, les éruptions volcaniques et sociales et toute la panoplie des soubresauts qui alimentent depuis des siècles la chronique de ces Joyeux Tropiques. J'écris d'une île convulsive...» (Xavier Orville, C'est la mer que j'écris, «Notre librairie», 143, janvier-mars 2001, p. 40). E «convulsa» è anche la lingua di Orville, ricca di giochi di parole e di sperimentazioni linguistiche, a cui fa eco uno stile ludico e allo stesso tempo critico, che vuole rappresentare l'esuberanza di un'isola dai mille volti, in cui molteplici culture si sono confrontate e affrontate nei secoli. Il lavoro fatto sul testo da Vilma Porro traduce quella terra, quella lingua, rendendola accessibile al pubblico italiano. Allo scopo di rendere più agevole la lettura, il romanzo è corredato da un breve glossario di parole chiave, che spiega il significato di alcuni termini creoli (ex. chibichou, 
zouk, corossol), o di alcuni elementi caratterizzanti della realtà antillana, come le stagioni (hivernage, carême).

2 Sagace parabola sul potere, il romanzo si conclude con un post-scriptum dell'autore, che mostra come non sia solamente la narrazione dell'ascesa e caduta di un dittatore antillano, ma piuttosto una riflessione su «tutti i commendatori. Quelli di altrove. D'Africa. D'America, d'Europa, d'Asia. Quelli del mondo intero.» (p. 118). È a loro che Xavier Orville, «in tutta ingenuità democratica», dedica il suo romanzo. 